\title{
Sustainable operations
}

\section{Günter Fandel ${ }^{1} \cdot$ Peter Letmathe $^{2} \cdot$ Thomas Stefan Spengler $^{3} \cdot$ Grit Walther $^{4}$}

Published online: 15 March 2021

(c) The Author(s) 2021

JEL Codes Q56 $\cdot \mathrm{M} 11 \cdot \mathrm{M} 14 \cdot \mathrm{L} 31$

Sustainability is one of the mega topics of this century. Whether climate change or resource efficiency-sustainability is driving the transformation of entire industries and has found its way into all scientific disciplines. It is therefore only logical that social and environmental aspects of production and logistics have been discussed in the business management literature and in practice for many years now. The current special issue reflects this development and covers a wide range of topics in the research field of sustainable operations.

Production in particular is responsible for many environmental and social impacts. This responsibility starts with the designing of global value chains and the studying of heterogeneous environmental and social standards applied. In this context, it is of great importance that sustainability aspects are correctly documented and assessed. Only then can such aspects be adequately considered in production planning in order to ensure the preservation of resources as part of a circular economy. These developments are associated with substantial changes in corporate structures and routines that do not only lead to internal changes but that also transform entire industries and markets. Hence, these changes open up opportunities for new companies that position social and environmental goals at the forefront of their activities. The five papers included in this special issue cover such developments in sustainable operations, addressing key aspects that are relevant to the companies involved, to their supply chains, and to our society.

Peter Letmathe

letmathe@controlling.rwth-aachen.de

1 Center of Production Economics and Decision Systems, FernUniversität in Hagen, Universitätsstr. 41, 58084 Hagen, Germany

2 Chair of Management Accounting, School of Business and Economics, RWTH Aachen University, Templergraben 64, 52062 Aachen, Germany

3 Chair of Production and Logistics, TU Braunschweig, Mühlenpfordtstraße 23 (6. Stock), 38106 Brunswick, Germany

4 Chair of Operations Management, School of Business and Economics, RWTH Aachen University, Kackertstr. 7, 52072 Aachen, Germany 
Petra Dickel, Monika Sienknecht, and Jacob Hörisch's article, "The early bird catches the worm: an empirical analysis of imprinting in social entrepreneurship", analyzes motivations and experiences that may lead to social entrepreneurship. Their empirical study highlights that childhood experiences in particular may be formative for later entrepreneurs. Therefore, the authors recommend that aspects of social entrepreneurship should be made more tangible in the upbringing of children.

Tim Gruchmann, Annika Mies, Thomas Neukirchen, and Stefan Gold address social tensions in companies, which are related to increasing automation and workplace design. Based on three case studies and a mixed-methods approach, the authors show that performance and belonging aspects play critical roles in the redesigning of workplaces as a result of technological change. During this change process, paradox tensions between employees and human resource managers may be subject to critical disputes and need to be resolved.

A circular economy requires used products and their resources to be collected in order to preserve their value for further economic activities. The corresponding collecting and processing costs play a crucial role when configuring a collection system. In his article "On the influence of collection cost on reverse channel configuration", Jochen Gönsch shows that manufacturers prefer collection by third parties and that they need to organize their reverse supply chains accordingly.

Assessing the sustainability of global supply chains is an extraordinarily complex problem, since ecological, economic, and social aspects have to be considered simultaneously and in their interaction. Christian Thies, Carsten Kieckhäfer, and Thomas Stefan Spengler show in their paper "Activity analysis based modeling of global supply chains for sustainability assessment" that spatial-based approaches can be helpful when considering different supply chain configurations. The approach is illustrated by the supply chain of lithium-ion batteries.

The paper by Christian Scheller, Kerstin Schmidt, and Thomas Stefan Spengler focuses on the interaction of recycling and production activities of lithium-ion batteries. The authors illustrate novel planning approaches that take into account both forward and reverse material flows. By analyzing five scenarios, the authors demonstrate that recycling, remanufacturing, and reusing lithium-ion batteries is economically feasible and that centralized planning approaches can increase the economic efficiency of manufacturing and recycling companies.

We are excited about all the strong theoretical and practical implications of these five articles and wish all readers an insightful read. We would also like to sincerely thank all reviewers and authors for their contributions to this special issue.

Funding Open Access funding enabled and organized by Projekt DEAL.

Open Access This article is licensed under a Creative Commons Attribution 4.0 International License, which permits use, sharing, adaptation, distribution and reproduction in any medium or format, as long as you give appropriate credit to the original author(s) and the source, provide a link to the Creative 
Commons licence, and indicate if changes were made. The images or other third party material in this article are included in the article's Creative Commons licence, unless indicated otherwise in a credit line to the material. If material is not included in the article's Creative Commons licence and your intended use is not permitted by statutory regulation or exceeds the permitted use, you will need to obtain permission directly from the copyright holder. To view a copy of this licence, visit http://creativecommons.org/ licenses/by/4.0/.

Publisher's Note Springer Nature remains neutral with regard to jurisdictional claims in published maps and institutional affiliations. 